\title{
Study of Alkali Halide Solid Solutions by Scanning Electron Microscopy and X-ray Diffraction
}

\author{
R. Rodriguez-Mijangos ${ }^{1}$, O. Hernández-Negrete ${ }^{2}$, R. C. Carrillo-Torres ${ }^{2}$, F. J. Carrillo-Pesqueira ${ }^{2}$, M. E. \\ Alvarez-Ramos $^{2}$ and J. Hernández-Paredes ${ }^{2}$ \\ 1. Departamento de Investigación en Física (DIFUS), Universidad de Sonora (UNISON), Blvd. Luis \\ Encinas J y Rosales s/n Col. Centro, Hermosillo, Sonora, C.P. 83000, México \\ 2. Posgrado en Nanotecnología, Departamento de Física, Universidad de Sonora (UNISON), Blvd. Luis \\ Encinas J y Rosales s/n Col. Centro, Hermosillo, Sonora, C.P. 83000, México
}

Alkali halide materials are ionic crystals with the chemical formula MX, where $\mathrm{M}$ is an alkali metal ( $\mathrm{Li}$, $\mathrm{Na}, \mathrm{K}, \mathrm{Rb}, \mathrm{Cs}$ ) and $\mathrm{X}$ is a halogen $(\mathrm{F}, \mathrm{Cl}, \mathrm{Br}, \mathrm{I})$. They can form solid solutions by substitution between the alkali metals, the halogens or both [1]. Solid solutions are widely studied with the aim to understand the phase selection during solidification. The objective of the present work is to determine the phases present in the final microstructure of a crystalline material obtained from the melt of various alkali halide salts.

The samples were obtained by the Czochralski technique from a melt at $750{ }^{\circ} \mathrm{C}$ prepared by mixing equal molar fractions of pure $\mathrm{KBr}, \mathrm{RbCl}, \mathrm{RbBr}, \mathrm{KI}$ and $\mathrm{RbI}$ salts. SEM and EDS analyses were carried out with a FEG-SEM JEOL JSM-7800F, $15 \mathrm{keV}$ under backscatter conditions and an EDS Bruker QUANTAX XFlash 6|60. Powder X-ray diffraction data were collected at room temperature in the transmission mode on a Bruker D8-ADVANCE diffractometer equipped with a focusing curved Ge (111) crystal $\left(\lambda_{\mathrm{Cu}-\mathrm{K} \alpha 1}=1.540596 \AA\right)$ and a LynxEye detector. Le Bail fit [2] was carried out using GSAS [3] and the EXPGUI [4] interface.

The BSE image in Figure 1 shows the typical microstructure of the specimen with the elemental X-ray maps. It is observed that $\mathrm{Rb}$ is distributed in all the microstructure, while $\mathrm{K}$ is mainly present in areas that contain $\mathrm{Br}$ and $\mathrm{Cl}$. Besides, $\mathrm{I}$ is in vicinity of the $\mathrm{Br}$ and $\mathrm{Cl}$ rich areas. These results suggested that the microstructure comprises two phases $\mathrm{MH}(\mathrm{M}: \mathrm{K}, \mathrm{Rb} ; \mathrm{H}: \mathrm{Cl}, \mathrm{Br}$ ) and $\mathrm{RbI}$. X-ray diffraction analysis also suggested the presence of two phases. Figure 2 shows the Le Bail fit of the X-ray powder diffraction pattern. The data is well fitted to two phases with cubic symmetry (Fm-3m) and cell parameters: $a=b=c=6.6564(8) \AA$ and $a=b=c=7.24329(18) \AA$. These parameters are close to those found in the PDF cards 73-387 $\mathrm{Rb}\left(\mathrm{Cl}_{0.6} \mathrm{Br}_{0.4}\right)$ and 6-218 RbI. However, there are shifts of the peaks for both phases which are attributed to the presence of $\mathrm{K}$ in the $\mathrm{MH}$ solid solution and $\mathrm{Br}$ in the $\mathrm{RbI}$ phase, according to EDS analysis.

These preliminary results would indicate that only two phases were formed. There was strong partition of $\mathrm{K}$ towards $(\mathrm{Rb}, \mathrm{K})\left(\mathrm{Br}_{1-\mathrm{x}}, \mathrm{Cl}_{\mathrm{x}}\right)$ compound, which favoured the formation of $\mathrm{RbI}$ and $(\mathrm{Rb}, \mathrm{K})\left(\mathrm{Br}_{1-\mathrm{x}}, \mathrm{Cl}_{\mathrm{x}}\right)$ phases.

References:

[1] M. Athee, Annales Academiae Scientiarum Fennicae Series A6: Physica, 313 (1969) 1-11.

[2] A. Le Bail, Powder Diffraction, 20 (2005) 316-326. 
[3] A. C. Larson, R. B. Von Dreele, 2000, General Structure Analysis System (GSAS), Report LAUR 86-748, Los Alamos National Laboratory, Los Alamos, New Mexico.

[4] B. H. Toby, J. Appl. Crystallogr., 34 (2001) 210-213.

[5] The authors thank CONACyT (México).
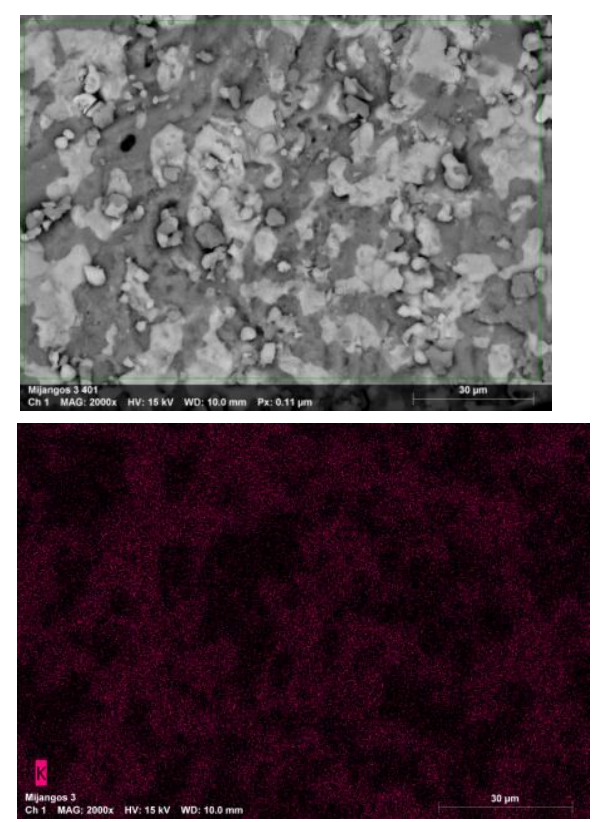
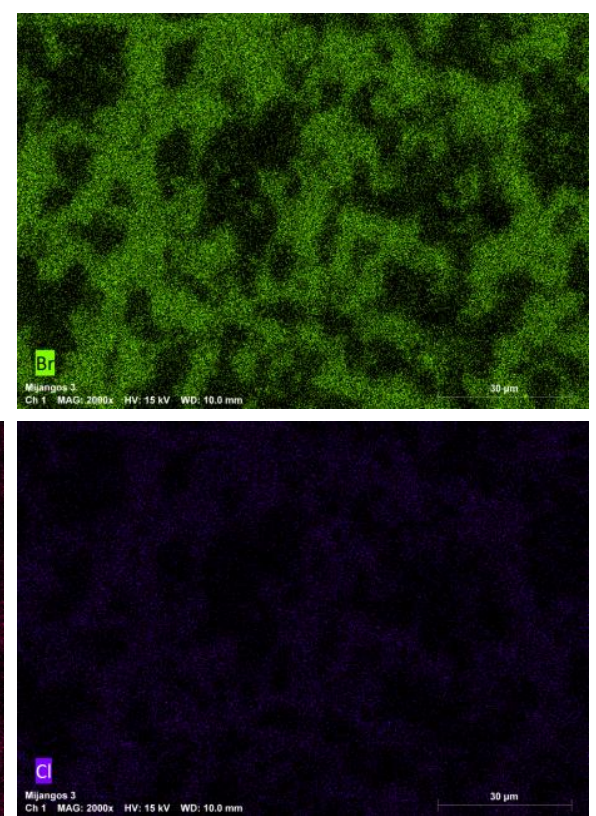
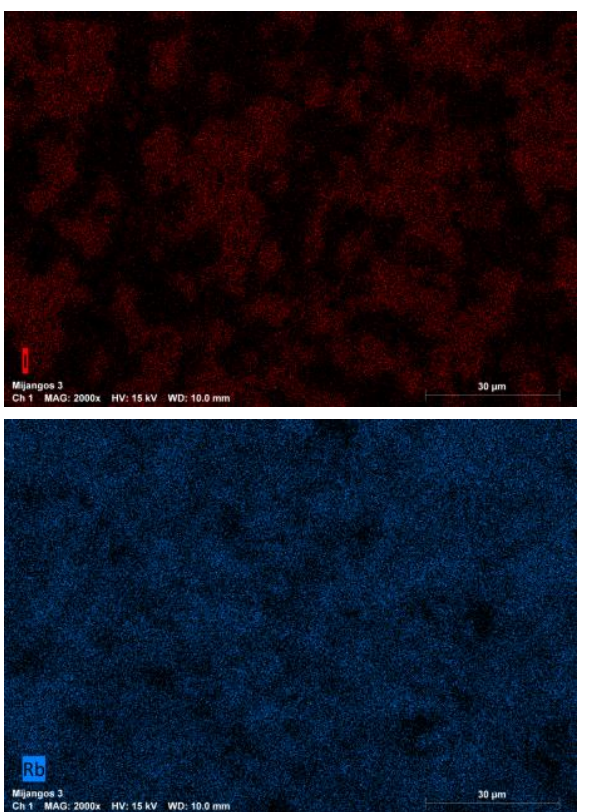

Figure 1. Elemental X-ray map showing the distribution of the elements in the specimen. (Br) green area; (I) red area; $(\mathrm{K})$ violet area; $(\mathrm{Cl})$ indigo area and $(\mathrm{Rb})$ blue area.

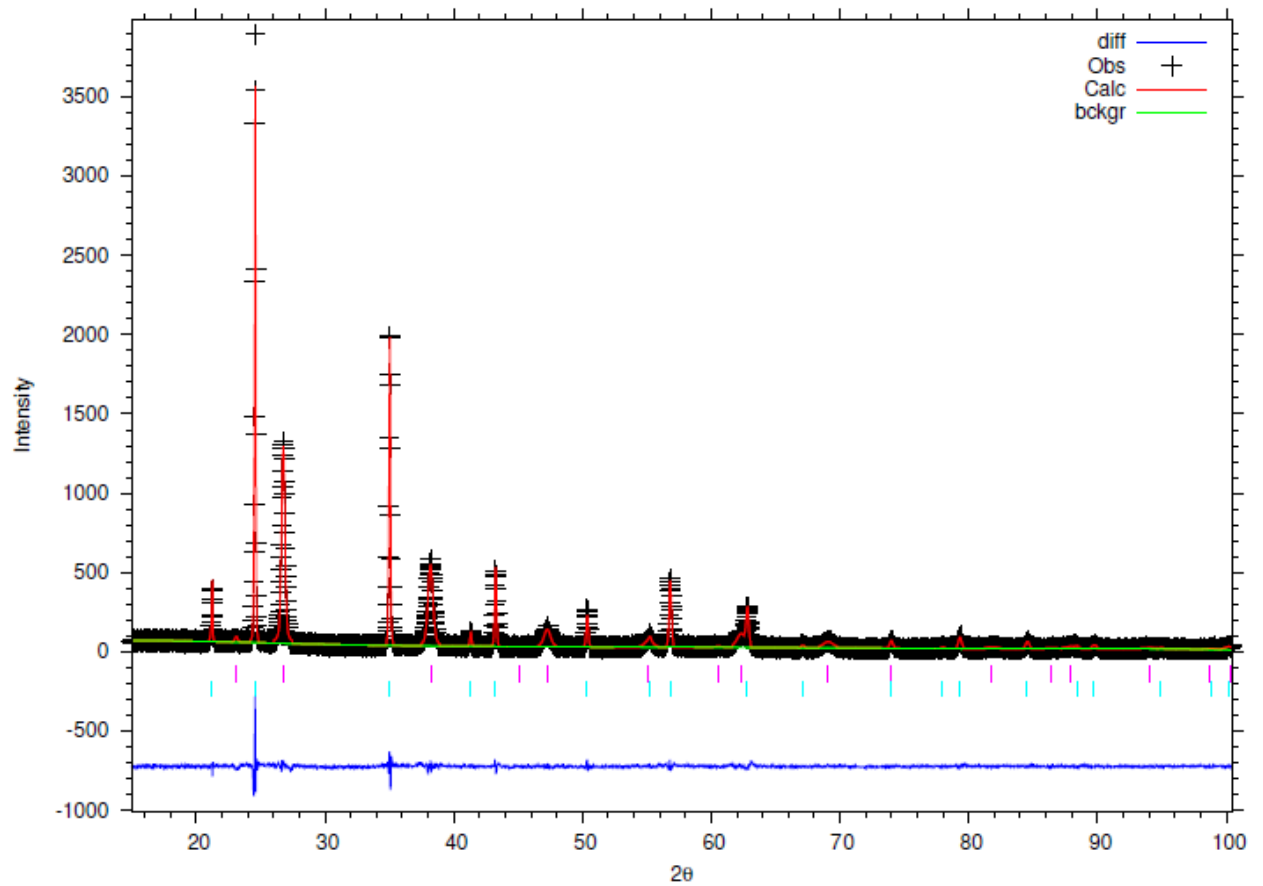

Figure 2. Le Bail fit for the sample prepared in this work. Experimental (black marks), calculated (red line) and difference (blue line). Magenta bars symbolise the positions of the $\mathrm{MH}(\mathrm{M}: \mathrm{Rb}, \mathrm{K} ; \mathrm{H}: \mathrm{Br}, \mathrm{Cl})$ phase; cyan bars symbolise the positions of the RbI phase. 